\title{
AN IN VITRO STUDY TO ASCERTAIN THE TRANSVERSE STRENGTH OF DENTURE BASE RESIN REINFORCED WITH TWO DIFFERENT FIBERS AND THEIR COMBINATION
}

\author{
${ }^{1}$ Abhinav Agarwal, ${ }^{2}$ Manesh Lahori, ${ }^{3}$ Dharmesh Kumar \\ Department of Prosthodontics \\ K.D. Dental College and Hospital, Mathura
}

\section{Research} Article

\begin{abstract}
:
Purpose: The purpose of this study was to compare the transverse strength of denture base resin reinforced with two distinct fibers and their combination with the denture base resin without any reinforcement.

Materials and Method: A total 40 test samples of clear heat cure resin were fabricated with the help of a customized metallic die and divided in to four groups- Group1: samples fabricated with clear acrylic resin without any reinforcement(Control group),Group2: samples reinforced with carbon fiber epoxy resin composite block, Group3: samples reinforced with glass fiber epoxy resin composite block, Group 4: samples reinforced with combination of carbon and glass fiber epoxy resin composite block. After finishing and polishing all the samples were having final dimension of $3 \mathrm{~cm} \times 1 \mathrm{~cm} \times 0.3 \mathrm{~cm}$ with a \pm 0.02 error measured with digital vernier caliper. Samples were immersed in water for 7 days in an incubator. A 3-point bend test was done in a universal testing machine, and load to fracture was recorded (MPa). Statistical analysis was performed using one way analysis of variance (ANOVA) followed by tukey HSD post-hoc test to compare mean transverse Strength in four groups.

Results: Group 2 and group 4 showed highest strength with significant difference with all other groups and non-significant with each other. Group1(control group) showed lowest transverse strength among all the groups.

Conclusion: carbon fiber and glass fiber alone provided either good transverse strength or good esthetics respectively while unique combination of carbon and glass fiber epoxy resin composite significantly increased the transverse strength of acrylic resin along with good esthetics.
\end{abstract}

\section{Key words:}

Reinforced,

carbon fiber,

glass fiber,

transverse strength.

Source of support : Nil

Conflict of interest: None
INTRODUCTION: Acrylic resin is the most widely used denture base material. It has many advantages, particularly its appearance and ease of manipulation, but it has certain poor mechanical properties which lead to fracture of the prostheses.[1] Acrylic resin exhibits notch sensitivity, a problem with the labial frenum that can initiate midline fractures.[2] Usually a fracture can be attributed to the mechanical properties of the acrylic resin, unsatisfactory occlusion, or poor fit of the prosthesis while accidental trauma is also reported as a frequent cause. A fracture is primarily initiated by material fatigue causing a crack which emerges from a location of high stress described as sharp frenum notches, diastemas, and maxillary tori.[3] Attempts have been made to improve the mechanical properties of acrylic resin by giving maximum bulk to the material in the region most heavily stressed, by copolymerization and cross linking, reinforcement with glass fibers, aluminum and sapphire whiskers, polycarbonates, carbon fibers, and addition of metal strengtheners. "Schrieber" described the addition of carbon fiber to acrylic resin to form a composite material. He found that such a composite material had a greater transverse strength than high impact resins.[3] Manley et al reported that no untoward tissue reactions occurred with this material.[4]

Carbon fibers were first made commercially by Edison in the late 19 th century by carbonizing thin bamboo shoots and cotton fibers.[5] The bulk of carbon fiber is made from polyacrylonitrile by heating in air at $200^{\circ} \mathrm{C}$ to $250^{\circ} \mathrm{C}$ and then 
in an inert atmosphere at $1200^{\circ} \mathrm{C}$. This process removes $\mathrm{H} 2$, $\mathrm{N} 2$, and $\mathrm{O} 2$ leaving a chain of carbon atoms and thus forming carbon fibers. ${ }^{5}$ Glass fibers were also tested in some studies to improve mechanical properties of denture base polymers which especially resulted in improved fatigue resistance and good esthetic properties.[6]

Polymers used in prosthetic dentistry are often multiphase acrylic resin system made from pre polymerized powder beads (predominantly PMMA) and a liquid of monomers such as methyl methacrylate (MMA) with a cross-linking monomer. Because such a polymer monomer mixture or dough has relative high viscosity, adequate impregnation of reinforcing fibers with resins has been difficult to achieve. The experiments show clearly that strands are more efficient strengtheners than are woven mats.[7] Therefore, it may be possible to reduce the amount of fiber included in a denture. This study was carried out to ascertain the transverse strength of standard-sized acrylic resin specimens reinforced with adequately impregnated blocks of carbon fibre and glass fibre in individual and mixed composition. According to null hypothesis $\left(\mathrm{H}_{0}\right)$ there was no difference in transverse strength of acrylic resin with or without any reinforcement.

MATERIALS AND METHOD: A customized metallic die was made to prepare the patterns of length $-3 \mathrm{~cm}$, width $-1 \mathrm{~cm}$ and thickness- $0.3 \mathrm{~cm}$ [Figure1]. Putty consistency of polyvinyl siloxane impression material was used to make patterns for test samples . All patterns were devoid of voids and had even contours and uniform dimensions. The patterns were invested in the metal flask to obtain the desired replica of test samples . The DPI clear acrylic resin was used to fabricate the samples.

Test samples were divided into 4 groups: Group 1: Test samples fabricated with clear acrylic resin without any reinforcement (control group),Group 2: Test samples reinforced with carbon fiber epoxy resin composite block, Group 3: Test samples reinforced with glass fiber epoxy resin composite block,Group 4: Test samples reinforced with combination of carbon and glass fiber epoxy resin composite block.

Fabrication of samples for group 1: The upper and lower members of flask were painted with separating media. The powder and liquid heat cure material were mixed in a close porcelain container according to the manufacturer's instructions and packed in dough stage. Later flask was pressed under the spring loaded clamp and left for bench curing for 30 minutes followed by curing at $74^{\circ} \mathrm{C}$ for 8 hours [Figure 2].

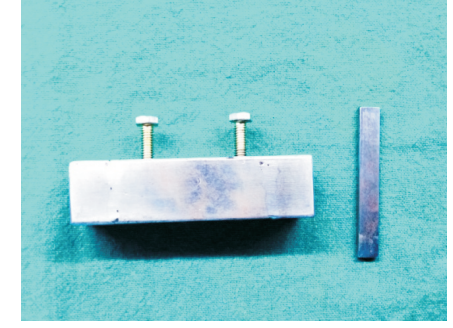

Figure 1: Customized die

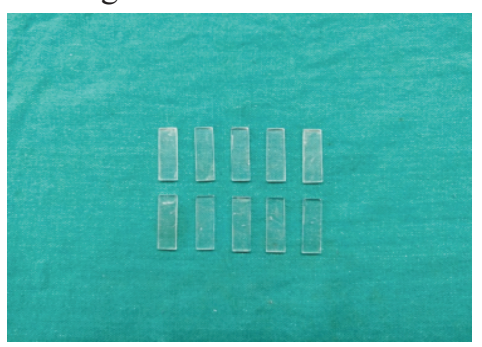

Figure 2: Control group

Preparation of fiber group for reinforcement: Three types of fiber groups were used for reinforcement: Carbon fiber epoxy resin composite block, Glass fiber epoxy resin composite block and combination of carbon and glass fiber epoxy resin composite. The $1^{\text {st }}$ and $2^{\text {nd }}$ groups were prepared by curing the carbon and glass fiber sheets with epoxy resin simultaneously. The third group was prepared by sandwiching carbon fiber sheet between glass fibers sheets and cured with epoxy resin. The composite sheets were then cut into the blocks of length $-20 \mathrm{~mm}$, width $-3 \mathrm{~mm}$ and thickness $-1 \mathrm{~mm}$. These prefabricated composite blocks were manufactured by CF Composites.

Modification in flasking technique: The fiber blocks were getting displaced from its desired position because distribution of excess resin dough was not uniformly directed like conventional flasking procedure. Hence, it was modified by providing 8 channels along the cross section of long axis of the replica in both upper and lower member of the flask. These channels were given to provide a directional escape route to the excess dough. Four channels were made away from replica and four were made towards the centre of the replica.

Fabrication of samples reinforced with composite blocks: All the composite blocks were of similar dimensions and impregnated as follows-The replica in the flask was painted with separating media. The dough of heat cure resin was prepared, divided into two equal halves and placed over the replica in upper and lower member of the flask. Cellophane sheets were placed over each half of the flask . Before closing the flask a paper was placed between both the halves to prevent sticking of cellophane sheets. Flask was pressed 
under the hydraulic press to remove the excess material. Flask was then removed from the press and opened to remove cellophane sheets and excess layer of material. Silane was painted over the composite block to improve adhesion between composite block and acrylic resin. After 15 minutes composite block was wet with monomer and placed at the centre of each replica in the lower member of flask. Flask was closed gently and pressed slowly under the spring loaded clamp and left for 30 minutes for bench curing, later it was placed in the acrylizing unit for curing at $74^{\circ} \mathrm{C}$ for 8 hours. This procedure was followed to fabricate test samples for the remaining three groups; carbon fiber, glass fiber and combination of carbon fiber and glass fiber test groups [Figure 3-5].

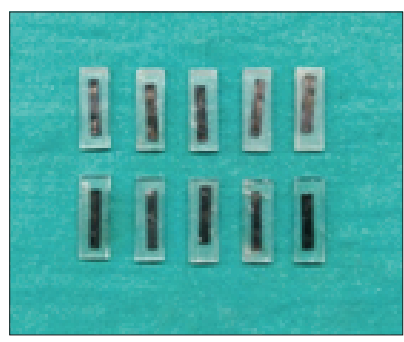

Figure 3: Carbon fiber group
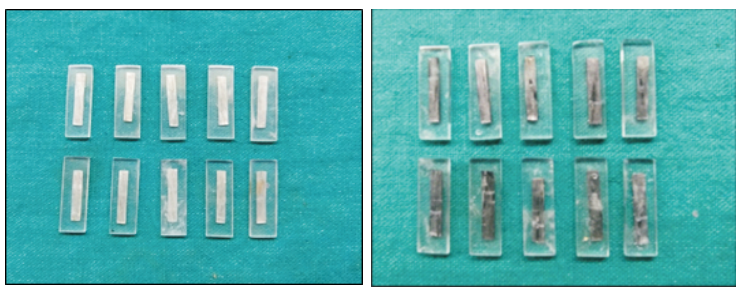

Figure 4:Glass fiber group Figure 5: composite fiber group After curing all the samples were removed from flask. Excess residues were trimmed off and assessed for porosities. They were smoothened with 400, 600 and 1000 grit silicon carbide sand paper and polished by using dry cotton buff. All the samples were having final dimension of $3 \mathrm{~cm} \times 1 \mathrm{~cm} \times 0.3 \mathrm{~cm}$ with a \pm 0.02 error measured with digital vernier calliper (Mukesh Trading Co, India). Continued water uptake after curing may cause denture base materials to undergo changes. That is why all the samples were immersed in $37^{\circ} \mathrm{C}$ distilled water for a minimum of 7 days for saturation in a $37^{\circ} \mathrm{C}$ incubation chamber.

The transverse strength of the each sample was measured during a three point bending test using a digital testing machine (Apex Assessment Pvt Ltd Ghajiabad, UP, India) [Figure 6]. The testing jig was made of two parallel rods, with a third rod centered above parallel and between the first 2, giving a 3 point load to the acrylic block. Force was applied to the centre of each block [Figure 7]. The three point bending jig was set to have a span of $15 \mathrm{~mm}$, and a $2500 \mathrm{~kg}$ load is applied with acceleration of $5 \mathrm{~mm} / \mathrm{min}$. The formula used to determine the flexural strength was

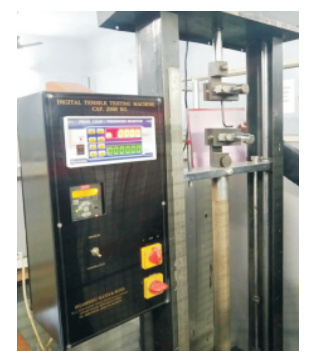

Figure 6: Digital testing machine

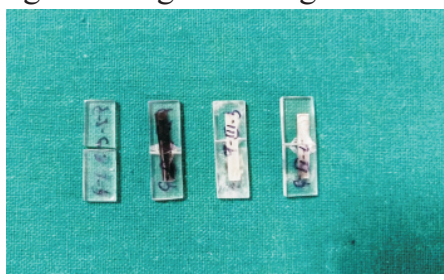

Figure 7: Samples after testing

The transverse strength of the each sample was measured during a three point bending test using a digital testing machine (Apex Assessment Pvt Ltd Ghajiabad, UP, India) [Figure 6]. The testing jig was made of two parallel rods, with a third rod centered above parallel and between the first 2, giving a 3 point load to the acrylic block. Force was applied to the centre of each block [Figure 7]. The three point bending jig was set to have a span of $15 \mathrm{~mm}$, and a $2500 \mathrm{~kg}$ load is applied with acceleration of $5 \mathrm{~mm} / \mathrm{min}$. The formula used to determine the flexural strength was $\sigma=\mathrm{FL} / \mathrm{bh}^{2}$. Where $\sigma$ is the bending stress, $\mathrm{F}$ is the force applied and $\mathrm{L}$ is the length span, $\mathrm{b}$ is the width of the specimen, $\mathrm{h}$ is the depth of the specimen. Mean and standard deviation were calculated. Results were analyzed using one way analysis of variance (ANOVA).

\section{RESULTS:}

Three point bent test was done and maximum load values were obtained and were converted into maximum bending stress with the formula, $\sigma=\mathrm{FL} / \mathrm{bh}^{2}$ Where $\sigma$ is the bending stress, $\mathrm{F}$ is the force applied and $\mathrm{L}$ is the length span, $\mathrm{b}$ is the width of the specimen, $h$ is the depth of the specimen.

Mean and standard deviation were calculated. Statistical analysis was performed using one way Analysis of Variance (ANOVA) [Table 1] \& [Graph 1] followed by Tukey HSD post-hoc test to compare mean transverse Strength in four groups [Table 2]. P-value less than 0.05 was considered as significant at $95 \%$ confidence level. The statistical software 
SPSS version 18.0 was used in the analysis. Group 2 and group 4 showed highest strength with significant difference with all other groups and non-significant with each other. Group 1 showed significant lower Flexural strength among all other groups.

Table No.1 Mean value and standard deviation of all the groups calculated using one way ANOVA test

\begin{tabular}{|c|c|c|c|c|c|c|c|c|c|}
\hline \multicolumn{10}{|c|}{ Descriptives } \\
\hline & \multirow[b]{2}{*}{$\mathrm{N}$} & \multirow[b]{2}{*}{ Mean } & \multirow[b]{2}{*}{$\begin{array}{l}\text { Std. } \\
\text { Deviation }\end{array}$} & \multicolumn{2}{|c|}{$\begin{array}{l}95 \% \\
\text { Confidence } \\
\text { Interval for } \\
\text { Mean }\end{array}$} & \multirow[b]{2}{*}{ Minimum } & \multirow[b]{2}{*}{ Maximum } & \multirow[b]{2}{*}{$\begin{array}{l}\text { F- } \\
\text { value }\end{array}$} & \multirow[b]{2}{*}{$\begin{array}{l}\text { p- } \\
\text { value }\end{array}$} \\
\hline & & & & $\begin{array}{l}\text { Lower } \\
\text { Bound }\end{array}$ & $\begin{array}{l}\text { Upper } \\
\text { Bound }\end{array}$ & & & & \\
\hline Group1 (CG) & 10 & 49.09 & 6.84 & 44.19 & 53.99 & 35.8 & 55.5 & \multirow{5}{*}{94.52} & \multirow{5}{*}{$<0.001$} \\
\hline Group2 (CF) & 10 & 107.06 & 9.92 & 99.97 & 114.15 & 92.9 & 120.1 & & \\
\hline Group3 (GF) & 10 & 80.33 & 8.70 & 74.11 & 86.55 & 65.4 & 90.3 & & \\
\hline $\begin{array}{l}\text { Group4 } \\
\text { (Composite) }\end{array}$ & 10 & 107.48 & 10.17 & 100.20 & 114.76 & 96.5 & 125.4 & & \\
\hline Total & 40 & 85.99 & 25.78 & 77.75 & 94.23 & 35.8 & 125.4 & & \\
\hline
\end{tabular}

Table No.2 : Tukay HSD test was conducted to compare all the four groups with each other and to determine level of significance

\begin{tabular}{|l|l|l|l|}
\hline (I) Group & (J) Group & Mean Difference (I-J) & Sig. \\
\hline \multirow{3}{*}{ Group1 (CG) } & Group2 (CF) & $-57.97000^{*}$ & $<0.001$ \\
\cline { 2 - 4 } & Group3 (GF) & $-31.24000^{*}$ & $<0.001$ \\
\cline { 2 - 4 } & Group4 (Composite) & $-58.39000^{*}$ & $<0.001$ \\
\hline \multirow{2}{*}{ Group2 (CF) } & Group3 (GF) & $26.73000^{*}$ & $<0.001$ \\
\cline { 2 - 4 } & Group4 (Composite) & -0.42 & 1 \\
\hline Group3 (GF) & Group4 (Composite) & $-27.15000^{*}$ & $<0.001$ \\
\hline *. The mean difference is significant at the 0.05 level. \\
\hline
\end{tabular}

Graph.1 Comparison of mean transverse strength among groups

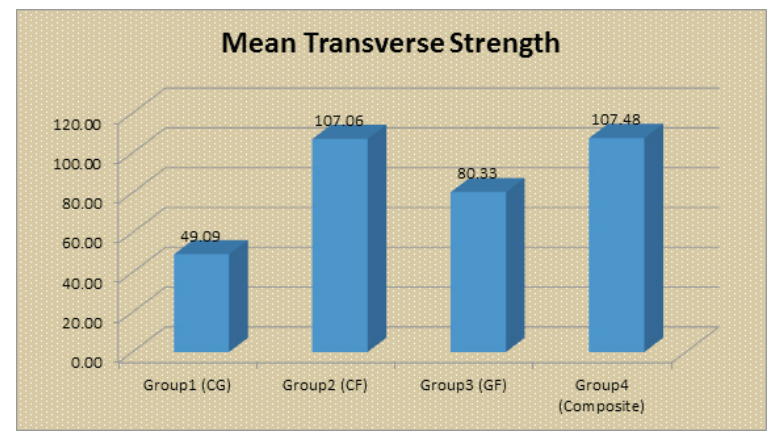

DISCUSSION:The material most commonly used for the fabrication of complete denture is polymethyl methacrylate (PMMA) denture base resin. This material is not ideal in every aspect, it is the combination of virtues rather than one single desirable property that accounts for its popularity and usage. Despite satisfying esthetic demands it is far from ideal in fulfilling the mechanical requirements of complete or partial denture prosthesis.[8]

Many approaches have been used in the past to strengthen the PMMA denture base resin such as incorporation of metal wire and various types of fibers which include glass fiber, sapphire whiskers fiber, aramid fiber, carbon fibers, nylon fibers and polyethylene fiber.[9-10]

Carbon fiber is used in many studies to improve the mechanical properties of the matrix because of its inherent high strength and optimal combination with the matrix. Mainly, carbon fibers have been used to enhance fatigue and impact strength.[11] Despite good mechanical properties, color of carbon fibers is not favorable. Glass fibers have been also considered as reinforcing materials for denture base resins because of their excellent aesthetics, superior strength, and good biocompatibility. Jaikumar et al found that acrylic resin specimens reinforced with glass fibers showed higher transverse strength compared to high impact denture base resins. The same results were reported by Hamouda et al. in 2014 as well Unalan et al. stated that the form of glass fiber could also affect the transverse strength of reinforced denture base resins.[12]

The polymer matrix forms a continuous phase that surrounds the fibers thus, the applied loads are transferred from the polymer matrix to the fibers. One of the most important factors that affect the strength of the composite is proper adhesion of the fibers to the polymer matrix. This adhesion makes it possible to transfer the stresses from the matrix to the fibers. The stiffness of the fibers is an important characteristic for strengthening of brittle materials like denture base resins. However, these fibers might break-up the homogeneous matrix of acrylic resin due to poor interface between fiber and resin affecting the mechanical properties. In order to avoid this problem, many studies advocating the surface treatment of fibers have been reported in the literature.[13-14]

In this study the transverse strength of clear acrylic resin block was compared with acrylic blocks reinforced with the fiberepoxy resin composite blocks. These composite blocks were made by carbon fiber and epoxy resin, glass fiber and epoxy resin and carbon fiber sandwiched between glass fibers followed by epoxy resin curing. 


\section{CONCLUSION:}

Within the limitations of this study following conclusions were draw

1. Transverse strength of reinforced acrylic resin was found to be significantly higher than the acrylic resin without any reinforcement.

2. Mean transverse strength of resin reinforced with carbon fiber was found to be more compared to glass fiber group.

3. Acrylic resin reinforced with carbon fiber alone and in combination with glass fiber showed significantly high transverse strength compared to other.

4. There was no significant difference between transverse strength of carbon fiber group and combination of carbon fiber and glass fiber composite group.

Clinical Implications: Most of the fibers used in the past as reinforcement either had good transverse strength or good esthetics, to overcome this a unique combination of glass fiber and carbon fiber was used in this study which combined strength of carbon fiber and esthetic properties of glass fiber. These glass fibers can be further stained to match with the shade of denture base to achieve optimal esthetics. Finally the choice of reinforcement to be used still depends on clinical condition and operator preference.

Suggestions for future study: Further studies are required to compare strength of acrylic resin with different type of bonding mechanisms of these fibers.

\section{REFERENCES:}

1. Schneider RL. Diagnosing functional complete denture fractures. J Prosthet Dent 1985;54:809-814.

2. Vallittu PK, Lassila VP, Lappalainen R. The effect of notch shape and self cured acrylic repairing on the fatigue resistance of an acrylic resin denture base. J Oral Rehabil 1996;23:108-113.

3. Schreiber CK. Polymethyl methacrylate reinforced with carbon fibers. Br Dent J. 1971;130:29-30.

4. Manley TR, Bowman AJ, Cook M. Denture bases reinforced with carbon fibers. $\mathrm{Br}$ Dent $\mathrm{J}$. 1979;146:25.

5. Jenkins GM, Kawamura AK. Polymeric Carbons Carbon Fibres, Glass and Char. Cambridge. 1976, Cambridge University Press.

6. Vallittu PK, Lassila VP, Lappalainen R. Transverse strength and fatigue of denture acrylic-glass fiber composite. Dent Mater 1994;10:116-121.
7. Yazdanie N, Mahood M. Carbon fiber acrylic resin composite: an investigation of transverse strength. J Prosthet Dent 1985;54:543-547. Amit V. Naik. Complete denture fractures- A clinical study. The Journal of Indian Prosthodontic Society. 2009;9:148-150

8. Amit V. Naik. Complete denture fractures-A clinical study. The Journal of Indian Prosthodontic Society. 2009;9:148-150.

9. John J, Shivaputrappa AG, Shah I. Flexural strength of heat-polymerized polymethyl methacrylate denture resin reinforced with glass, aramid, or nylon fibers. J Prosthet Dent. 2001;86:424-427

10. Fernanda Faot, Leonardo H V Panza, Renata C M Rodrigues Garcia, Altair Antoninha Del Bel Cury. Impact and flexural strength and fracture morphology of acrylic resins with impact modifiers. The Open Dentistry Journal. 2009:3:137-14.

11. Kristina Zukiene, Egidijus Zukauskas, Rymantas Jonas Kazys, Daiva Zeleniakiene, Virginija Jankauskaite. Structure - Impact properties relationships of carbon fiber reinforced polymethyl methacrylate composite. P Comp. 2019:40:333-341.

12. Unalan, I. Dikbas, O. Gurbuz. Transverse Strength of Polymethyl methacrylate reinforced with different forms and concentrations of E-Glass fibres. OHDMBSC. 2010;9:144-147.

13. Vallittu PK. Comparison of two different silane compounds used for improving adhesion between fibers and acrylic denture base material. J Oral Rehabil. 1993;20:533-539.

14. Solnit GS. The effect of methyl methacrylate reinforcement with silane treated and untreated glass fibers. J Prosthet Dent. 1991;66:310-314.

\section{CORRESPONDING AUTHOR :}

\section{Dr. Abhinav Agarwal}

K.D. dental College and Hospital

NH-2, Near Chattikara, Mathura-281006

E-mail:drabhi_17@yahoo.co.in 